\title{
THE DISTRIBUTION OF METHIONINE LOCI IN NEUROSPORA CRASSA
}

\author{
NOREEN E. MURRAY \\ Department of Microbiology, University of Birmingham *
}

Received 5.iv.60

\section{INTRODUCTION}

IN Salmonella typhimurium (Demerec and Demerec, I956; Hartman, I956; Hartman et al., I958) and Escherichia coli (Morse, Lederberg and Lederberg, I956a and $b$ ) functionally related genes are often situated close together and arranged in the same sequence as the steps of the biochemical pathway which they control. Examples of this " assembly-line" arrangement have not been reported in organisms other than bacteria. In Neurospora crassa there are examples of very close linkages between pairs of genes making different contributions to a biosynthetic pathway (Stadler, 1956; de Serres, 1956), and Horowitz (1955) pointed out that there was some evidence for the clustering of methionine loci in linkage group IV, and cysteine loci in group VI.

Methionine mutants are divisible into four groups on the basis of precursor utilisation and the sequence of methionine synthesis indicated by these data is cysteine $\rightarrow$ cystathionine $\rightarrow$ homocysteine $\rightarrow$ methionine (Horowitz, 1947; Fischer, 1957). Most of the evidence from Neurospora crassa (Horowitz, I955), and from a variety of microorganisms (Steinberg, I94I; Lampen, Roepke and Jones, I947; Hockenhull, I949; Clowes, I958), indicates that the initial stages of methionine synthesis, in which cysteine is produced from inorganic sulphate, involve the reduction of sulphate via sulphite and thiosulphate before the sulphur is incorporated into an organic compound.

By the isolation and classification of a large number of methionine mutant strains it was hoped that previously unknown methionine genes might be discovered and that subsequent mapping would reveal any clustering of the methionine loci.

\section{MATERIALS AND METHODS}

(i) Mutants. The stocks of methionine mutant strains comprise 12 collected by Beadle and Tatum (I945) and I 72 new ones. The previously reported mutants, described by Emerson (1950), Barratt et al. (1954) and Stadler (1956), are 387o6 and 35599 (me-I) ; H98 and 48004 (me-2); 36104 (me-3);39816 (me-4); 9666 and $86304(m e-5) ; 35809(m e-6) ; 84605$ (cys-1) ; 38401 (cys-2) and 39 Io3 (no locus symbol given).

Of the new mutant strains 163 were isolated following ultraviolet irradiation of the wild type stock Emerson $a$. The other new mutants were obtained following ultraviolet irradiation of the prototrophic stock Y8743 (Catcheside, I954), or of

\footnotetext{
* Present address : Department of Biological Sciences, Stanford University, Stanford, California, U.S.A.
} 
$a l-2,38 a$. All the strains isolated following ultraviolet irradiation of the Emerson $a$ stock were conidiate, and fertile, and readily formed a heterocaryon with an arginine mutant, $\mathrm{K}_{132}$ ( $\arg -5$ ), isolated after ultraviolet irradiation of the same wild type strain. The other new mutants and the stocks of Beadle's mutants were backcrossed repeatedly, usually three or four times, to wild type (Emerson $a$ or $A$ ) in order to select cultures which were conidiate, fertile and heterocaryon compatible with the test mutant, $\mathrm{K}_{\mathrm{I}} 32$.

(ii) Media. The standard minimal medium (VM) used was that of Vogel (1955) solidified, where necessary, by I.5 per cent. agar. Where it was desirable to induce a colonial growth (Tatum et al., I949) 0.5 per cent. sorbose and 0.1 per cent. sucrose (VSM) were substituted for the 2 per cent. sucrose. Crosses were made on Westergaard's medium (Westergaard and Mitchell, 1947). The appropriate supplements were added to the minimal media at the following rates (mg./ litre) : L-arginine monohydrochloride, 400 ; choline, 2.4 ; +DL-allo-cystathionine, 500 ; cysteic acid, 200 : L-cysteine, 200 ; cytidylic acid 100 ; L-histidine monohydrochloride, 300; DL-homocysteine, 200; DL-methionine, 250 ; calcium pantothenate, 1o ; para-amino-benzoic acid, o.or and tryptophan, $5^{\circ}$.

(iii) Methods. The cultures were incubated at $25^{\circ} \mathrm{C}$., or at $34^{\circ} \mathrm{C}$. when temperature-sensitive markers were being scored, and ascospore germination was stimulated by heat treatment for 50 minutes in an oven at $56^{\circ} \mathrm{C}$.

Tests for precursor utilisation were made on appropriately supplemented plates of VSM. Heterocaryon tests were made by superimposing aqueous suspensions of the conidial components on plates of VSM. Preliminary linkage data for biochemical mutants were obtained from repulsion phase crosses by counting wild type recombinants among ascospores germinated on plates of VSM. Confirmation of linkage was sought from ordered tetrads.

\section{EXPERIMENTAL RESULTS}

\section{(i) Isolation of mutants}

The mutant strains were isolated by a filtration concentration technique following ultraviolet irradiation or conidial suspensions (Catcheside, I954 and personal communication). The method was modified by appropriate supplementation of the media, in order to select for special classes of mutants. Two experiments of this type gave neither sulphite mutants nor cysteine mutants unable to utilise thiosulphate.

\section{(ii) Precursor utilisation}

All the methionine mutant strains were tested to determine which of the reported intermediates would support their growth. Sulphite and thiosulphate media were made by replacing the sulphate of the stock medium by equivalent amounts of sulphur as magnesium sulphite or thiosulphate respectively. Thiosulphate medium was also made by adding filter-sterilised sodium thiosulphate (A.R.) aseptically to autoclaved VSM to give a concentration of only io $\mu \mathrm{g}$. of thiosulphate sulphur per $\mathrm{ml}$. In this way it was hoped to differentiate between mutants able to utilise thiosulphate and any cysteine mutants growing on possible traces of sulphide.

Sulphite, cysteic acid, homocystine, choline and para-aminobenzoic acid did not support the growth of any of the mutant strains. The remainder of the results are listed in table $\mathrm{I}$. 


\section{(iii) Heterocaryon complementation}

The mutants could be divided into groups such that members of a group did not form prototrophic heterocaryons with all, or most, members of their own group but did so with all members of the other groups. The failure of compatible mutants to complement demonstrates that their mutant genes are physiologically allelic. Wherever

TABLE I

Precursor utilisation and inter-allelic complementation

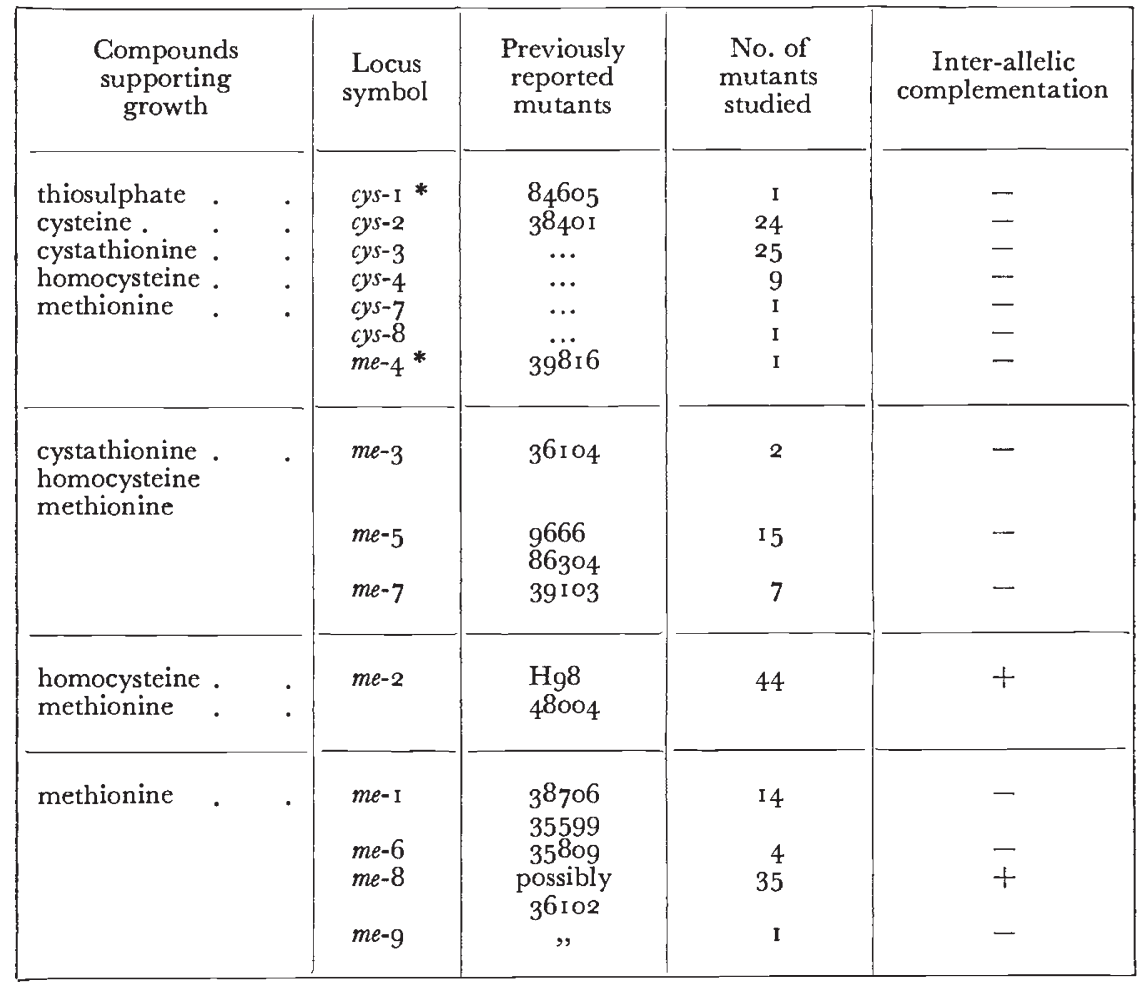

* Growth slight when sulphur concentration reduced to Io $\mu \mathrm{g}$. $/ \mathrm{ml}$.

$$
t=\text { present } \quad-=\text { absent }
$$

crosses between such strains were fertile no, or few, wild type recombinants were obtained, indicating that mutant genes designated allelic by physiological criteria are located within a short region of the chromosome. Interallelic complementation was found at two loci and this will be discussed elsewhere. The locus symbols me-7, $-8,-9$, and cys $-3,-4,-7,-8$ were assigned to the groups of mutants presumed to represent previously unrecognised genes. Since a sulphite and a cysteine locus had been reported by Phinney (1948), but no symbols assigned to them, $c y s-5$ and -6 were left for them. The results are summarised in table $\mathrm{I}$. 


\section{(iv) Mapping and linkage data}

Initial experiments were designed to detect linkage between methionine mutants and markers in linkage group IV, and between cysteine mutants and markers in group VI. It was known that $m e-5$ was situated in the right arm of linkage group IV (Barrett $e t$ al., 1954) and that cys-I and -2 were located very close to each other in linkage group VI (Stadler, I956). When no evidence of either group IV or group VI linkage was obtained crosses were made,

TABLE 2

Analysis of tetrads from two-point crosses providing evidence of linkage

\begin{tabular}{|c|c|c|c|c|c|c|c|c|c|c|c|c|c|}
\hline \multicolumn{2}{|c|}{ Locus } & \multicolumn{7}{|c|}{ Ascus class (see below) } & \multirow{2}{*}{$\begin{array}{c}\text { Total } \\
\text { no. }\end{array}$} & \multicolumn{2}{|c|}{$\begin{array}{l}\text { Division II } \\
\text { segregation }\end{array}$} & \multicolumn{2}{|c|}{$\begin{array}{l}\text { Ditype } \\
\text { tetrads }\end{array}$} \\
\hline$a$ & $b \dagger$ & I & II & III & IV & V & VI & VII & & $\begin{array}{l}\text { Locus } \\
a\end{array}$ & $\underset{b}{\operatorname{Locus}}$ & $\mathrm{PD}$ & NPD \\
\hline$m \boldsymbol{e}-\mathbf{I}$ & $p y r-\mathrm{I}$ & I 6 & 0 & 0 & 2 & 2 & 0 & 0 & 20 & 4 & 2 & I 8 & 0 \\
\hline & pyr-3 & 3 & 0 & o & 5 & 6 & 0 & I & I 5 & I 2 & 7 & 9 & 0 \\
\hline$m e-2$ & col-I & 24 & 0 & 8 & 0 & 26 & 0 & I & 59 & 27 & 35 & 50 & 0 \\
\hline & hist-4 & I I & 0 & 4 & 0 & 9 & 0 & 0 & 24 & 9 & 13 & 20 & 0 \\
\hline & & 7 & 0 & 4 & 3 & 6 & 0 & I & 21 & 10 & I I & I3 & 0 \\
\hline$m e-7$ & sfo & I 4 & 0 & 0 & 0 & 0 & 0 & 0 & I 4 & o & 0 & I 4 & o \\
\hline$m e-8$ & $a d-4$ & 23 & 0 & 0 & 0 & I & 0 & 0 & 24 & I & I & 24 & 0 \\
\hline
\end{tabular}

\begin{tabular}{|c|c|c|c|c|c|c|c|}
\hline \multirow[b]{2}{*}{$a^{+} b \times a b^{+}$} & \multicolumn{7}{|c|}{ Ascus class * } \\
\hline & $\begin{array}{c}\mathrm{I} \\
a^{+} b \\
a^{+} b \\
a b^{+} \\
a b^{+}\end{array}$ & $\begin{array}{c}\text { II } \\
a^{+} b^{+} \\
a^{+} b^{+} \\
a b \\
a b\end{array}$ & $\begin{array}{l}\text { III } \\
a^{+} b \\
a^{+} b^{+} \\
a b \\
a b^{+}\end{array}$ & $\begin{array}{l}\text { IV } \\
a+b \\
a b \\
a^{+} b^{+} \\
a b^{+}\end{array}$ & $\begin{array}{c}\mathrm{V} \\
a^{+} b \\
a b^{+} \\
a^{+} b \\
a b^{+}\end{array}$ & $\begin{array}{l}\text { VI } \\
a^{+} b^{+} \\
a b \\
a^{+} b^{+} \\
a b\end{array}$ & $\begin{array}{l}\text { VII } \\
a^{+} b^{+} \\
a b \\
a^{+} b \\
a b^{+}\end{array}$ \\
\hline
\end{tabular}

* Catcheside (1951).

† All markers are located in linkage groups IV except $s f_{0}$ (VII) and ad-4 (III).

wherever possible, to markers in both arms of the remaining linkage groups and evidence of linkage was sought. The preliminary data indicated that $m e-\mathrm{I}$ and $m e-2$ were in linkage group IV, $m e-7$ in group VII and $m e-8$ in group III. Me-3 (36104) and $m e-6$ (35809) had been located previously (Barratt et al., I954) in linkage groups $\mathrm{V}$ and I respectively.

More detailed information was sought from ordered tetrads and the data, summarised in tables 2 and 3 , are from asci in which at least one member of each spore pair germinated, except that the cross $m e-7 \times s f o$ includes asci in which a minimum of one of each of three spore pairs germinated.

These data confirm that $m e-\mathrm{I}, m e-2$ and $m e-5$ are in the right arm of linkage group IV and also indicate that $m e-2$ and $m e-5$ could be 
situated close together. The uncorrected distance from the centromere of $m e-2$, based on 229 asci, is 20 units, and this locus is distal to pyr-3 and tryp-4 but proximal to pan-1, col-1, hist-4 and cot. The 54 asci from the cross $m e-5 \times \operatorname{tryp}-4$, pan-1 demonstrate that $m e-5$ is distal to tryp-4 and has an uncorrected distance from the centromere of

\section{TABLE 3}

Analysis of tetrads from three-point crosses localising me-2 and me-5 within linkage group IV

\begin{tabular}{|c|c|c|c|c|c|c|}
\hline \multirow{2}{*}{ Cross } & \multicolumn{3}{|c|}{ Cross-overs } & \multirow{2}{*}{$\begin{array}{l}\text { Ascus } \\
\text { class * }\end{array}$} & \multirow{2}{*}{\multicolumn{2}{|c|}{$\begin{array}{l}\text { No. of } \\
\text { tetrads }\end{array}$}} \\
\hline & No. & Region & Type & & & \\
\hline $\begin{array}{c}\dagger^{1}(a) \text { me- } 2 \times \\
\text { tryp-4, pan-1 }\end{array}$ & $\begin{array}{l}0 \\
1 \\
2\end{array}$ & $\begin{array}{c}\cdots \\
\text { I } \\
\text { II } \\
\text { III } \\
\text { I-II } \\
\text { II }\end{array}$ & $\begin{array}{c}\ldots \\
\ldots \\
\ldots \\
\ldots \\
3 \text { str. } \\
4 \text { str. }\end{array}$ & $\begin{array}{r}1 \\
21 \\
9 \\
5 \\
31 \\
4\end{array}$ & Total & $\begin{array}{r}25 \\
6 \\
4 \\
3 \\
1 \\
1 \\
40\end{array}$ \\
\hline $\begin{array}{c}\dagger^{2}(b) m e-5 \times \\
\text { tryp-4, pan-I }\end{array}$ & $\begin{array}{l}0 \\
1 \\
2\end{array}$ & $\begin{array}{c}\cdots \\
\text { I } \\
\text { II } \\
\text { I-II }\end{array}$ & $\begin{array}{c}\ldots \\
\cdots \\
\cdots \\
2 \text { str. or } 4 \text { str. }\end{array}$ & $\begin{array}{r}1 \\
21 \\
9 \\
13\end{array}$ & Total & $\begin{array}{r}24 \\
18 \\
9 \\
3 \\
54\end{array}$ \\
\hline
\end{tabular}

* Whitehouse (1942).

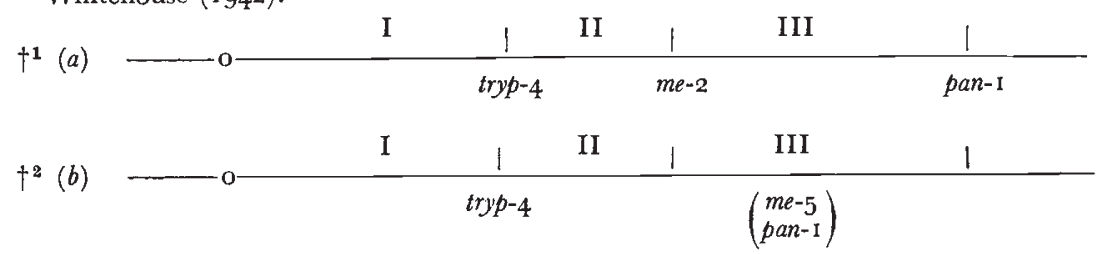

25 units. No recombination was observed between me-5 and pan-I; hence the order of these two loci, with respect to the centromere, was not established. Crosses between $m e-2$ and $m e-5$ mutants were made and the data from random spores indicated a recombination frequency of 3.3 per cent. when corrected for the presence of pseudowild type individuals. This figure may be low for it has since been observed that some stocks carry deleterious viability factors which permit germination, but prevent the growth of the spores on VSM.

The mutant $39103(m e-7)$ was associated with the centromere 
region of linkage group VII and no second division segregation was found among 44 tetrads.

A further methionine gene $(m e-8)$ was located in the right arm of linkage group III and data from $5^{8}$ tetrads gave a centromere distance of 5 units.

The linkage data so far obtained do not permit the allocation of mutant $\operatorname{Pi}_{5}{ }^{6}$ (me-9) to a linkage group, but confirm that me-9 is distinct from the three other genes (me-1, $m e-6$ and $m e-8)$ which are associated with the methylation of homocysteine to methionine.

Although little progress was made with the mapping of the cysteine mutants no evidence was obtained for the presence of any cys loci, other than $c y s-1$ and $c y s-2$, in linkage group VI.

\section{DISCUSSION}

Three methionine genes, arranged in the order of the biochemical steps which they control, have been associated with the right arm of linkage group IV, but they do not form a cluster in which the genes are adjacent to each other. Horowitz and co-workers (Fling et al., 1957) similarly found no evidence for a tight clustering, but reported that $m e-2$ was proximal and $m e-5$ distal to cot. The recent evidence of Mr E. G. Barry (personal communication) that $m e-\mathrm{I}$ is situated between $p d x-\mathrm{I}$ and $p y r-3$ limits the proximity of $m e-\mathrm{I}$ and $m e-2$ to between 5 and 10 map units. Thus $m e-\mathrm{I}, m e-2$ and $m e-5$ may be situated within a distance of approximately 15 map units.

Fischer (1957) demonstrated the absence of the enzyme cystathionase I in the mutant strain 4894 and of cystathionase II in the strain $\mathrm{H}_{98}$ (me-2). Both of these enzymes cleave cystathionine, the former to yield cysteine and the latter to yield homocysteine. It was, therefore, of interest to know whether these two mutants were members of the postulated cluster. However, the mutant gene in 4894 is, on the basis of heterocaryon data, physiologically allelic to the me-7 gene in 39103 (Buss, 1944) and more recently Mrs M. K. Allen (personal communication) established that 4894 is located in linkage group VII, whereas $m e-2$ is in linkage group IV.

The lack of mutants unable to reduce sulphate to sulphite (cys-5), or of mutants unable to reduce thiosulphate to sulphide (cys-6), and the abundance of mutants unable to reduce sulphite to thiosulphate is surprising. The heterocaryon tests indicated that these mutants are divisible into seven groups of physiological alleles. The members of two of these groups are alleles of $c y s-1$ and $c y s-2$ respectively. Representatives of each of the five remaining heterocaryon groups showed no linkage to cys-1 or cys-2 but it has not been shown that these groups represent five different loci. If the early stages of methionine synthesis occur by a simple pathway of sulphate reduction the presence of seven distinct biochemical steps between sulphite and thiosulphate, each controlled by a separate gene, appears excessive. 


\section{SUMMARY}

Mutant strains of Neurospora crassa requiring methionine or its precursors, were isolated by a filtration concentration technique following ultraviolet irradiation. These and other strains were classified by the tests of precursor utilisation and heterocaryon complementation into seven groups of cysteine and eight groups of methionine mutant strains.

The methionine strains represent genes at eight different loci; of these three had been located previously and four of the remainder were assigned to definite regions of the linkage maps. No evidence for tight clustering of either the methionine or cysteine genes was obtained.

Inter-allelic complementation was demonstrated for two of the methionine genes.

Acknowledgments.-The author wishes to express her thanks to Professor D. G. Catcheside, F.R.s., for his encouragement and helpful criticism given throughout these investigations and to Dr D. D. Perkins for his interest during the writing of this paper. GratefuI thanks are due to both Professor Catcheside and Dr J. R. S. Fincham for donations of a number of mutant strains and to the Department of Scientific and Industrial Research for a maintenance grant.

\section{REFERENCES}

BARRATt, R. W., NEWMEYER, D., PERkins, D., AND GARNJOBST, L. I954. Map construction in Neurospora crassa. Adv. in Genetics, 6, I-93.

BeAdle, G. W., AND tatum, E. L. 1945. Neurospora. II. Methods of producing and detecting mutations concerned with nutritional requirements. Amer. $\mathcal{F}$. Bot., 32, 678-686.

BUss, H. I944. The genetics of methionineless mutants of Neurospora crassa. M.A. Thesis. Stanford University.

CAtcheside, D. G. I95I. The Genetics of Microorganisms. Pitman and Sons, London. CATCHeside, D. G. I954. Isolation of nutritional mutants of Neurospora crassa by filtration enrichment. J. Gen. Microbiol., I I, 34-36.

CLowEs, R. C. 1958. Nutritional studies of cysteineless mutants of Salmonella typhimurium. F. Gen. Microbiol., i8, I40-I 53 .

DEMEREC, M., AND DEMEREC, z. E. I956. Analysis of linkage relationships in Salmonella by transduction techniques. Brookhaven Symposia in Biol., 8, 75-87.

DE SERRES, F. J., JR. 1956. Studies with purple adenine mutants in Neurospora crassa. I. Structural and functional complexity in the ad-3 region. Genetics, $4 I, 668-676$.

EMErson, s. 1950. Competitive reactions and antagonisms in biosynthesis. Cold Spring Harbor Symp. Quant. Biol., 14, 40-48.

FISCHER, G. A. 1957. The cleavage and synthesis of cystathionine in a wild type and mutant strains of Neurospora crassa. Biochim. et Biophys. Acta, 25, 50-55.

FLING, M., HOROWITZ, N. H., AND REINKING, V. 1957. Linkage of some methionine mutants of Neurospora. Microbial Genet. Bull., 15, I 2-1 3.

HARTMAN, P. E. 1956. Linked loci in the control of consecutive steps in the primary pathway of histidine synthesis in Salmonella typhimurium. Genetic studies with bacteria. Carnegie Inst. Wash. Publ., No. 162, 35-62.

hartman, P. E., hartman, z., serman, D., AND loper, J. G. 1958. Genetic complementarity in histidineless Salmonella typhimurium. Proc. Xth Inst. Congr. Genetics, Montreal, 2, I I 5-II 6. 
Hockenhull, D. J. D. I949. The sulphur metabolism of mould fungi. The use of biochemical strains of Aspergillus nidulans in elucidating the biosynthesis of cystine. Biochim. et Biophys. Acta, 3, 326-335.

Horowrtz, N. H. 1947. Methionine synthesis by Neurospora. F. Biol. Chem., I7I, 255-264.

Horowrtz, N. H. 1955. Discussion. Symposium on Amino Acid Metabolism. Baltimore: Johns Hopkins Press.

LAMPEN, J. O., ROEPKE, R. R., AND JONES, M. J. I947. Studies on sulphur metabolism of Escherichia coli. III. Arch. Biochem., 13, 55-66.

MORSE, M. L., LEDERBERG, E. M., AND LEDERBERG, J. I956a. Transduction in Escherichia coli K-1 2 . Genetics, 4I, I42-I 56.

MORSE, M. L., LEDERBERG, E. M., AND LEDERBERG, J. 1956b. Transductional heterogenotes in Escherichia coli. Genetics, 4 I , 758-779.

PONTECORvo, G. 1956. Allelism. Cold Spring Harbor Symp. Quant. Biol., 21, I 7 I -I 74 PHINNEY, B. o. 1948. Cysteine mutants in Neurospora. Genetics, 33, 624.

STADLER, D. R. 1956. A map of linkage group VI of Neurospora crassa. Genetics, $4 I, 528-543$.

STEINBERG, R. A. 194I. Sulphur and trace element nutrition of Aspergillus niger. 7. Agric. Res., 63, rog-127.

TATUM, E. L., BARRATt, R. W., AND CUTTER, V. M. 1949. Chemical induction of colonial paramorphs in Neurospora and Syncephalastrum. Science, 109, 509-5 I I.

vogel, H. J. 1955. A convenient growth medium for Neurospora. Microbial Genet. Bull., 13, 42 .

WESTERgaARD, M., AND MITChell, H. K. 1947. Neurospora $V$. A synthetic medium favoring sexual reproduction. Am. F. Bot., 34, 573-578.

whitehouse, H. L. к. 1942. Crossing-over in Neurospora. New Phyt., 6I, 23-62. 